\title{
UN ACERCAMIENTO A LA MEDICINA POPULAR EN UBRIQUE (1996-1997)
}

\section{Orestes RODRÍGUEZ AGUADO}

D.U.E. Médico de equipo de transporte de críticos de ambulancias Cádiz, para la empresa pública de emergencias sanitarias de Andalucía Trabajo premiado por la Real Academia de Medicina y Cirugía de Cádiz en el año 1999; Premio "Visitador Médico"

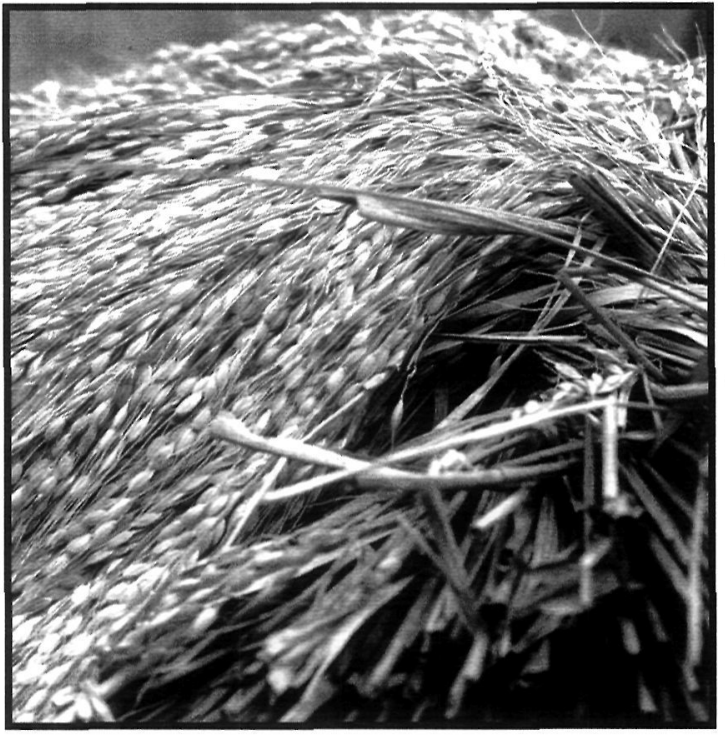

AN APPROACH TO POPULAR MEDICINE IN UBRIQUE (1996-1997)

7 he need to cure illness is inherent to evolution of human mankind. In its developmen-

1 tal process as a civilization, the means for this aim have accompanied the increasing knowledge in all areas of wisdom. As technique improved, ancient methods were forgotten or relegated by the emergent knowledge.

Regarding Medicine, on the contrary, the essence of illness having not been known or accepted by healthy and sick has allowed techniques, remedies and methods to live through modern Medicine and be used nowadays.

The chosen setting for this work is Ubrique, where 43 interviewed people have furnished us with information on disorders or health problems and useful remedies.

\section{RESUMEN}

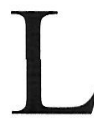

a necesidad de curar una enfermedad es consustancial a la evolución de la especie humana. En el proceso de desarrollo como civilización, los mecanismos empleados para conseguir este fin han ido parejos con el aumento de conocimientos en diferentes ramas del saber. Conforme iba avanzando la técnica, otros mecanismos más antiguos quedaban relegados en segundo término o, incluso, eran definitivamente dados de lado en beneficio del saber emergente.

En Medicina, en cambio, la esencia de la enfermedad, no bien conocida o asimilada por las personas enfermas y sanas, ha permitido que técnicas, remedios y formas de actuar que se podría creer quedaron superadas por otra Medicina más tecnificada hayan perdurado y sean incluso ampliamente utilizadas en la actualidad.

El lugar escogido para la realización del trabajo es Ubrique, donde se han entrevistado 43 personas que han aportado información diversa tanto sobre enfermedades o problemas de salud como sobre los remedios más útiles.

\section{INTRODUCCIÓN}

La extensión de la asistencia sanitaria a la población en zonas rurales podría hacer pensar que iban a desaparecer técnicas que han pasado de padres a hijos en la "curación" de numerosas dolencias. Parece que la Medicina Científica sustituye a la Medicina Popular existiendo un retroceso en el conocimiento de remedios caseros, probablemente debido a la creciente urbanización y a la influencia del moderno sistema sanitario.

En la práctica, sin embargo, la recurrencia a sanadores, curanderos, santones, etc, no indica que 
ésta sea la tónica general de la comunidad. En realidad, el Sistema de Salud se ve complementado por prácticas de medicinas alternativas, constituyéndose en una oferta paralela que es utilizada a discreción. Además, la existencia de procesos para los que es útil según los sanadores y los propios afectados sólo una cura mágica, les otorga un monopolio en la identificación (sería algo conflictivo hablar de diagnóstico tradicional) y tratamiento de estas entidades. Representa un ejemplo de esto, la dedicación especializada a las enfermedades infantiles y femeninas provocadas "mágicamente" como el "mal de ojo" y el "mal aire". A este respecto, resulta interesante considerar la "teoría de las lagunas" que se refiere a la cobertura que la Medicina Popular hace de las "lagunas" asistenciales del sistema sanitario o su misma constitución en sistema alternativo al propio sistema sanitario de prestación de servicios.

Añadido a la atención complementaria, la prestación en sí provoca la constitución del curandero en un competidor del médico al curar mediante la aplicación de remedios naturales.

El lugar donde hemos pasado la encuesta es Ubrique, un pueblo de la Sierra Norte de Cádiz, con una población de 18.212 habitantes $(9.068$ varones y 9.144 mujeres). En el plano sanitario, dispone de Centro de Salud donde existen consultas de Medicina General, Pediatría, Enfermería, Rayos X y Asistencia Social. La riqueza económica se fundamenta en la marroquinería (manufactura de la piel), constituyéndose en una fuente de ingresos de primer orden, Otros sectores productivos son la agricultura, turismo y ganadería.

La abundancia de libros publicados sobre remedios populares, algunos con gran rigor científico y otros con un carácter más divulgativo, ratifica la importancia de este campo en todo el mundo. Gordon (1997) analiza la importancia de las medicinas alternativas, y cita que en 1990 se gastaron en EEUU. 13.700 millones de dólares y un 34\% de los estadounidenses recurrían a algún tipo de terapia alternativa. Destaca el hecho de la constitución en el seno de los Institutos Nacionales de la Salud norteamericanos, de una Oficina de Terapias Alternativas, con un presupuesto escaso $(0,1 \%$ del total) pero indicativo del interés para empezar a trabajar en este campo. El abordaje de este estudio, necesariamente requerirá un doble acercamiento desde la perspectiva antropológica y de la Salud Pública.

Se pretende responder aquellas cuestiones que permitan acercarnos a la realidad social y sanitaria de esta tierra intentando alcanzar los siguientes objetivos:

1. Comprobar la existencia de conocimientos en Ubrique sobre remedios populares basados en plantas, técnicas, ensalmos, etc.

2. Conocer los intervalos de edad en los que se encuentran las personas que saben de remedios utilizables.

3. Investigar la existencia en la población de la creencia en el mal de ojo y formas de tratamiento del mismo.

4. Averiguar el vocabulario popular y la asignación que éste hace a las enfermedades y afecciones.

5. Compilar los procesos más tratados y sus remedios.

6. Establecer si existe asistencia a sanadores, curanderos, etc., en qué procesos y cómo son tratados.

\section{MATERIAL Y MÉTODOS}

Se ha pasado una encuesta abierta con cuestiones agrupadas en campos relacionados, incluyendo los datos generales del encuestado que son necesarios para el tratamiento estadístico de la información. Un grupo de preguntas admite contestaciones libres por parte de la persona entrevistada lo que le permite aportar información variada relacionada con el tema de la encuesta. Las cuestiones relativas a las plantas medicinales representan un sector de trabajo interno del investigador que no necesariamente debían ser contestadas por los entrevistados. (Tabla 1).

\section{DATOS GENERALES DEL ENCUESTADO}
1. Sexo.
2. Edad.
3. Estudios.
4. Ocupación.

SOBRE LOS REMEDIOS

1. Remedio empleado.

2. ¿De quién lo aprendió? 
3. Tipos de uso:

- Mágico.

- Medicinal.

- Otros.

4. Proceso de transformación. Preparación.

5. Forma de uso.

6. Además del remedio, ¿se recita alguna oración, conjuro o ensalmo?

SOBRE LA PLANTA MEDICINAL.

1. Nombre vulgar.

2. Nombre científico.

3. Familia.

4. Partes empleadas en Medicina Popular.

5. Composición y/o principios activos.

6. Acciones de la planta.

7. ¿Para qué se usan?

SOBRE LAS CONSULTAS CON CURANDEROS O SANADORES

1. ¿Acude a curanderos?

2. ¿Desde cuándo?

3. ¿Por qué?

4. ¿Dónde?

5. ¿Qué le mandó?

6. ¿Hubo mejoría?

7. En las últimas cuatro semanas, ¿recibió tratamiento médico?

8. ¿Para qué?

EN ESTE ESPACIO EN BLANCO, ANOTE TODA LA INFORMACIÓN QUE USTED CONOZCA SOBRE EL TEMA DE LA ENCUESTA

Tabla 1. Modelo de encuesta pasada a las personas entrevistadas en Ubrique

Para la realización de este proyecto, se ha contado con la colaboración como encuestadores de los participantes en un curso de formación continuada para celadores y auxiliares de clínica que son oriundos de la población. Previo al comienzo de la labor entrevistadora, se les ha instruido en detalles respecto de la misma para no influir en el entrevistado, recoger estrictamente lo que éste diga sin añadir aportaciones personales, etc.

El trabajo de campo fue realizado entre el segundo semestre de 1995 y el segundo de 1996. Los encuestadores han escogido a los entrevistados por razones de accesibilidad en lo que se conoce como muestreo probabilístico de conveniencia.

En total se han entrevistado a 43 personas, de las que 30 son mujeres y 13 son hombres, con un arco de edad que va desde los 26 a los 85 años. La media de edad es 51,73 años con una desviación típica de 16,81 años. (Tabla 2).

\section{INTERVALOS DE EDADES}

$$
\begin{aligned}
& 21-25=1 . \\
& 26-30=4 . \\
& 31-35=4 . \\
& 36-40=2 . \\
& 41-45=3 \\
& 46-50=5 \\
& 51-55=4 \\
& 56-60=7 \\
& 61-65=6 . \\
& 66-70=0 . \\
& 71-75=5 . \\
& 76-80=2 . \\
& 81-85=2 .
\end{aligned}
$$

Tabla 2. Intervalos de edades y frecuencias absolutas de las mismas.

Las personas que han aportado información a través de las entrevistas presentan estudios y ocupaciones laborales variadas. (Tablas 3 y 4 ).

\section{NIVELES DE ESTUDIO}

1. Sin estudios $=15$

2. Primarios $=14$

3. Graduado Escolar. $=3$

4. F.P. $1^{\circ}=3$

5. B.U.P., C.O.U., F.P. $2^{\circ}=2$

6. Universitarios $=1$

7. No especificados $=7$

Tabla 3. Nivel de estudios de los entrevistados agrupados en ciclos educativos completos. OCUPACIONES LABORALES

1. Ama de casa $=17$

2. Agricultor $=3$

3. Conserje $=1$

4. Chatarrero $=1$

5. Empresario $=4$

6. Limpiadora $=1$

7. Marroquinería $=4$ 

8. Parado $=1$
9. Pensionista $=7$
10. Sanadora $=7$
11. No especificada $=5$

Tabla 4. Ocupaciones laborales habituales de los entrevistados. Nótese que se aceptan como actividades laborales, situaciones como "parado" y "pensionista".

\section{RESULTADOS}

Se exponen seguidamente las afecciones tratadas y los remedios empleados que, como podemos comprobar, son variados. Se plantean situaciones en las que uno de los remedios se utiliza para enfermedades diferentes $\mathrm{y}$, a su vez, encontramos dolencias abortadas de maneras distintas. (La descripción seguirá un criterio de asociación por órganos y aparatos, citando el remedio y su forma de aplicación, de forma que cuando se repitan remedios en trastornos diferentes, sólo se consignará ese número de orden).

\section{SISTEMA NERVIOSO Y ÓRGANOS DE LOS SENTIDOS}

\section{Aclarar las ojeras.}

- Compresas empapadas en infusión de hojas de té sobre los párpados.

\section{Alergias oculares.}

- Lavados de los ojos con infusión de pétalos de rosa blanca recogida en mayo.

- Inhalación de vapores de infusión de unciana.

\section{Conjuntivitis.}

- Inhalación de vapores de infusión de unciana, poleo, cáscara de piña (de pino piñonero), de plátano y algarroba.

- Lavados con infusión de pétalos de amapola enfriada.

- Lavados con infusión de granos de "sargatona".

\section{Dolor.}

- Infusión de raíz de cardo blanco.

\section{Dolor de cabeza.}

- Infusión de hojas y bulbo de cebolla.

- Hojas de parra sobre la cabeza. Parece que es relajante y refrescante.

- Zumo de naranja amarga.

- Compresas empapadas en infusión de tallos y hojas de beleño macho sobre la cabeza.

- Infusión en ayunas durante tres días de "gobiernazo". Si no hay mejoría se toman otras tres tazas. Es muy amargo y no se debe endulzar.

\section{Dolor de oído.}

- Aplicar en el oído unas gotas empapadas en la maceración de almendras machacadas en aceite de oliva. El producto preparado no pierde su efecto.

- Gotas de leche de burra sobre el oído.

- Gotas de leche materna sobre el oído. Hay dos versiones de este remedio: una indica la aplicación como se cita. Otra precisa que si es para curar a un hombre, la madre debe estar criando una niña; si es para una mujer, la madre debe estar criando un niño.

\section{Espinas y motas en el ojo.}

- Siete u ocho granos de sargatona dentro del ojo.

\section{Infecciones oculares.}

\section{Inflamación de los ojos.}

- Lavados de ojos con infusión de manzanilla.

\section{Jaqueca.}

- Inhalación de vapores de la cocción de hojas de eucalipto macho.

\section{Orzuelo.}

- Frotar en la ropa un anillo de oro y aplicar sobre el orzuelo.

- Una primeriza debe soplar tres veces seguidas al ojo. Repetir si es necesario.

\section{Problemas oculares.}

- Aplicar sobre el ojo agua de lluvia recogida en mayo.

\section{Sueño.}

- Infusión antes de dormir, de flores y hojas de matagallo.

\section{Tranquilizantes.}

- Beber tanto como se quiera de la infusión de tallo, hojas y fruto del "pan de conejo o de pastor". 
- Infusión varias veces al día de tallos y hojas de zarzaparrilla, secas o frescas.

- Infusión, con precaución, de una pizca de pétalos de amapola.

\section{AFECCIONES DE LA BOCA.}

\section{Dolor de muelas.}

- Aplicar localmente el producto de freír en aceite de oliva argamuza real.

- Masticar una ramita de torbisca.

- Masticar unas hojas de lapa.

- Poner un algodón empapado en la solución obtenida al dejar unas horas en agua botones florales de clavo. Actúa como antiséptico y analgésico.

- Colgar un trozo de corcho del pecho.

- Enjuagar con coñac mezclado con una cucharada de sal común.

- Infusión de tuna cocida.

- Infusión de gobiernazo, tres días, en ayunas.

\section{Dolor de la salida de los primeros dientes.}

- Colgar una pata de rana de la ropa interior del niño.

\section{Flemón dentario.}

- Enjuagues bucales de agua hervida con bicarbonato sódico.

\section{Prevención de la piorrea.}

\section{TRASTORNOS DEL METABOLISMO Y OTROS}

1. Afecciones orgánicas en general. No especificado por el informante.

- Comer el fruto de la zarza.

\section{Recuperar el apetito.}

- Beber agua "rejumbrosa" (sulfurosa).

- Poner en la boca del estómago por la noche una bola de masa de pan frito con vino. Se cubre con una gasa o venda.

- Tomar un huevo macerado en vino dulce de quina. Se deja en maceración tres noches al sereno.

\section{Colesterol.}

- Infusión en ayunas de raíz de acebuche.

- Infusión, durante nueve días, de la cocción en un litro de agua de "cebolla colorada", manzana "colorada", manzanilla y limón, descansando otros nueve días.

\section{Deshidratación.}

- Infusión de higos, de higuera bravía, higos chumbos, algarrobas tostadas y cáscara de tres altramuces con un chorrito de vinagre y agua.

\section{Estimulante, perder grasa y aportar vitaminas.}

- Comer ortiga frita en aceite.

\section{PIEL Y ÓRGANOS ANEJOS.}

\section{Alergia.}

- Beber tres tazas al día de una infusión de raíz, tallos y hojas de ortigas.

\section{Extracción de aguijones.}

- Aplicar un emplasto hecho con barro y orina. Dejar secar y retirar.

\section{Ahuyentar mosquitos.}

- Colocar como repelente una mezcla de vinagre y agua.

\section{Antiséptico.}

- Poner localmente una gasa empapada en la infusión del fruto o flor del candil.

- Algodón o gasa con infusión de tallos y hojas de vara estepa, enfriada, en la lesión.

\section{Astillas clavadas profundamente.}

- Colocar como parche hojas de almirón previamente machacadas. Cubrir con una venda o gasa para que no se caiga.

\section{Caída del cabello.}

- Aclarar el pelo con una cocción de tallos y hojas de beleño macho.

- Enjuagarlo con una infusión de ortiga (toda la planta menos la raíz).

- Frotar el pelo con la infusión de romero en vino.

\section{Crecimiento del cabello.}

\section{Dar brillo al cabello.}

\section{Fortalecimiento del cabello.}

- Aplicar sobre el pelo una mezcla de agua y zotal.

- Lavar el pelo con una infusión de jartavaca. 
10. Callos.

- Aplicar sobre la dureza una pasta formada por una mezcla de agua de cal y aceite.

- Tres veces al día, poner un paño humedecido en agua hervida con bicarbonato, sal y vinagre dejándolo unos minutos.

\section{Cicatrización de heridas.}

- Cubrir la herida con ceniza de chimenea o de brasero.

- En la lesión colocar unciana tostada y "majada".

- Lavar las heridas con una infusión de árnica.

\section{Cortes en la piel.}

- Raspaduras de cal sobre el corte. Si la herida no es muy profunda, actúa como cicatrizante.

\section{3. "Culebrina".}

- Aplicar con esparto una mezcla de vinagre y pólvora negra sobre el "animal" recitando al mismo tiempo una oración. Al terminar ésta se quema el esparto. Este remedio hay que aplicarlo como mínimo un día y nueve como máximo. $\mathrm{Al}$ arder el esparto se "quema el animal". Si la persona no está presente se reza igual la oración, también es efectiva. Las oraciones, conjuros, etc. se transmiten siempre de una persona mayor a otra menor, de lo contrario no se adquiere la gracia o el don para sanar. La oración debe aprenderse en la noche de San Juan o de Navidad, ya que sino, no es efectiva.

- Aplicación en el lugar de corteza frita de pero en aceite de oliva, tres o cuatro veces al día.

- Pasar por la "culebrina" esparto mojado en agua con sal durante nueve días, rezando una oración.

14. "Culebrina interior". Nos indica que estaba localizada en la espalda y afectaba al hígado.

- Imposición de manos del curandero en la parte afectada durante nueve días.

\section{5. "Diviesos".}

- Colocar sobre el grano dos veces al día una hoja de sanalotó quitándole el "pellejo" de un lado.

\section{Eczema.}

- Alcanfor aplicado diariamente.
17. Empeine. Por la descripción del proceso, parece tratarse de infecciones por hongos.

- Emplasto en la lesión de pólvora negra y vinagre.

- Frotar diariamente con batata de gamón granado partido por la mitad hasta que desaparezca el empeine.

- Gotas de zotal mezcladas con agua al acostarse. Humedecer el empeine lo menos posible.

\section{Erisipela. Algunos entrevistados la nombran} "dicipela".

- Infusión de flor de sauco.

- Aplicar con una gasa o paño una mezcla de azufre y agua.

- Cruz de lentisco macho colgada del cuello.

\section{Espinas.}

- Aplicar sobre la espina de la pasta formada al escupir sobre vesículas de "cochino" (cerdo) macho, cortadas en trozos pequeños.

\section{Espolones.}

21. Fístulas. Nos precisan que si la fístula, el grano o la úlcera son feos, jamás curarán.

- Infusión de hojas de lapa como antiséptico.

- Infusión de guisopilla encima de cada comida.

22. Granos. Para algunos entrevistados, "grano" engloba a fístulas, ganglios, abscesos, tumores o úlceras en la piel. Si presentan "boca" se les llama "avieso", también forúnculo si el grano es feo.

- Aplicación local de la raíz de argamuza real; es muy absorbente por lo que hay que tener cuidado.

- Cataplasma de "cardos volaores". Facilita su maduración.

- Hoja de "uña de león" aplicada como parche, abierta por la mitad y cubierta con una gasa.

- Hoja pequeña de maximina sobre el grano, sin tocar la parte sana.

- Emplasto de tuna previamente hervida y abierta por la mitad. Es la pala del higo chumbo.

- Infusión de hojas de "cardo correo" en ayunas. 


\section{Granos en la cabeza.}

24. “Golondrino" (Forúnculo).

- Aplicación local de la pasta formada de añadir al aceite caliente pan y azafrán.

\section{Hematomas.}

- Sanguijuela sobre el hematoma: absorbe la sangre y baja la inflamación.

\section{Heridas.}

- Barro recogido de un manantial o río de agua "rejumbrosa" (sulfurosa) sobre la lesión.

- Infusión de unciana sobre la herida.

\section{Desinfección de heridas.}

- Pasta formada de azufre frita en aceite.

- Compresas empapadas en infusión de árnica.

\section{Infecciones de la piel.}

29 Parásitos externos o gusanos de animales domésticos o de granja.

- Cruz de "cardos volaores" en el suelo en el lugar donde haya pisado el animal. Se caen solos los gusanos.

30. Pecas del cutis.

- Lavados durante una semana con la maceración de un botón de nácar en agua en una noche.

\section{Picaduras.}

- Cortar la circulación con un torniquete. Hacer un corte y extraer todo el veneno que se pueda. Aplicar calor con un cigarro o carbón. Tomar un purgante.

\section{Picadura de abeja.}

- Emplasto de raíz de cardo blanco machacada cubierta con una venda para que no se caiga.

\section{Picadura de alacrán o escorpión.}

- Emplasto con ajo machacado, aceite de oliva, tocino añejo, barro y orina todo cocido.

\section{Picadura de víbora.}

- Hacer un torniquete y un corte. Aplicar calor ( "yesca de las quejigas" quemada). Tomar aceite. La "yesca de las quejigas" es el alcornoque.
35. Cicatrización de las picaduras de mosquitos y "coquitos".

- Limpiar la picadura con algodón empapado en vinagre y agua.

\section{Picores.}

\section{Quemaduras.}

- Aplicación de una mezcla de agua y leche condensada.

\section{Sabañones.}

- Colocar sobre el sabañón, "sombreritos", a los que se les quita la membrana.

- Sumergir el pie en salmuera.

- Untar en el sabañón un limón calentado, al acostarse.

- Sumergir el pie en una cocción de matagallo. Otro entrevistado dice que los baños deben ser diarios durante nueve días.

\section{Sarna.}

\section{Sarpullidos.}

\section{Tiña.}

- Aplicación local de la cáscara o la mata tierna triturada de habas verdes.

- Poner el bálsamo formado con zotal aguado, una cucharada sopera de aceite y media cucharada de leche. Mejor si la leche es de cabra.

\section{Tumores.}

\section{3. Úlceras.}

44. Úlceras de la piel. (La diferencia entre úlceras y úlceras de la piel es establecida por el entrevistado).

- Emplasto formado por la mezcla de corteza de olmo mojada con vaselina a partes iguales.

\section{Verrugas.}

- Frotar con una hoja de mormera.

- Frotar con una hoja de higuera. La verruga en nueve días se cae.

- Frotar dos veces al día con ajos pelados. Una variante exige tirar el resto sobre un lugar (tejado) 
por el que no se vaya a pasar más.

- Enterrar un hueso de un animal que se haya recogido del campo. En quince o veinte días desaparecen las verrugas.

- Brotes de palmito tiernos previamente masticados sobre la verruga. En quince o veinte días la verruga se cae.

- Capturar una lagartija en luna menguante. Abrirla y colgarla bien alta de un árbol. Aplicar la sangre localmente. Cuando la lagartija empiece a secarse, la verruga empieza a caerse.

- En los días de luna llena frotar un garbanzo sobre la verruga hasta que el garbanzo "sude" o se ponga caliente. Repetir durante quince días.

- Tirar tantos garbanzos como verrugas haya a un pozo por el que no se vaya a pasar más.

- Cortar pelo de la coronilla del enfermo que se guarda el curandero, indicando a la madre que cuente diariamente en ayunas las verrugas, poniendo saliva en cada una de ellas. Es un caso descrito por una chica que fue al curandero y las verrugas le desaparecieron. Se recitaba también una oración: "Marrita, marrita, haz que se cure esta verruguita".

\section{ENFERMEDADES CARDIOVASCULARES Y DE}

\section{LA SANGRE}

\section{Anemias.}

- Fruto de la granada en ayunas.

- Infusión de pezuña de ternera o de cerdo.

- Jarabe de huevo y vino dulce de quina.

- Fruto de la zarza.

\section{Angina de pecho.}

- Infusión de flores y hojas de espino "majuleto".

\section{Circulación.}

- Infusión en ayunas de cebolla.

- Infusión en ayunas de cardos "volaores".

- Infusión en ayunas durante nueve mañanas de ramas y hojas de olivo "manzanillo".

- Ortiga (toda la planta) frita en aceite y comida.

\section{Hemorragia externa. Aplicada externamente.}

\section{Hemorragia interna.}

- Infusión de tallos y hojas de unciana.

- Infusión encima de cada comida de guisopilla.

\section{Infecciones de la sangre.}

- Infusión no en ayunas de raíz, tallos y hojas de zarzamora.

- Infusión, antes de dormir, de flores y hojas de matagallo.

- Infusión en ayunas de hojas de cardo "correo".

\section{Problemas cardiacos.}

- Infusión de tallos, hojas y flores de árnica seca.

- Infusión en ayunas durante nueve mañanas de nueve hojas de acebuche.

\section{Revitalizar la sangre.}

\section{Tensión arterial alta.}

- Infusión de hojas de olivo en ayunas. Puede bajar la tensión bruscamente.

- Infusión de manzanilla amarga seca sin endulzar. No tomar en ayunas porque puede descender bruscamente la tensión.

\section{INFECCIONES}

\section{Bajar la fiebre.}

- Emplasto de simiente de mostaza triturada colocada en los pies. Sujetar con una venda. Nos la describen como una planta parecida al jaramago.

\section{Fiebre del paludismo.}

- Tomar nueve ajos en ayunas durante nueve días. Beber encima vino dulce.

- En ayunas masticar tres altramuces secos nueve mañanas seguidas. Una variante consiste en masticar en ayunas durante dieciocho días: primero un altramuz, el día segundo dos, y así hasta llegar al día nueve. Después otros nueve días descontando un altramuz por día hasta llegar al día dieciocho que se mastica un altramuz.

- Infusión en ayunas nueve mañanas de "hierba del paludismo" (espiga entera menos la raíz). Nos comenta el entrevistado que él y sus hermanas padecieron de estas fiebres y desaparecieron tras tomar esta infusión, no volviendo a reaparecer jamás.

- Infusión en ayunas durante nueve mañanas de tallos y hojas de marrubio. La fiebre comienza a remitir a partir del tercer día.

- Infusión durante nueve mañanas de nueve 
ajos o números "nones"(tres o siete).

\section{Paludismo.}

- Tomar el zumo de tres limones mezclado con la yema y la clara de un huevo dejado previamente al sereno y bebido en ayunas.

\section{ALTERACIONES DIGESTIVAS}

\section{Acidez de estómago.}

- Infusión de limón entero con piel con dos cucharadas de miel.

\section{Diarreas.}

- Infusión de puntas y tallos de zarza. Pueden emplearse hojas secas o frescas.

- Infusión de salvia.

- Infusión de cardos volaores.

- Infusión de flor de cardillo o tagarnina seca, tanta como se desee.

- Infusión de tallos, hojas y flor de manzanilla amarga secadas y sin azúcar.

- Infusión de "pan de conejo", toda la planta menos la raíz.

- Infusión de corteza seca de granada.

\section{Diarreas crónicas. Les llaman también pujos.} En este caso, se estableció posteriormente un diagnóstico clínico de colitis ulcerosa.

- Infusión de flor de tagarnina recogida en luna menguante.

\section{Dolor de barriga de los animales.}

- Beber vino y aceite de oliva mezclados.

- Beber una copa de vino al que se añade un carbón ardiendo.

- Infusión de hojas de "matagallo" macho.

- Compresas sobre la zona dolorida empapadas en la cocción de manteca de cerdo blanca sin sal, vinagre y cebolla majada.

- Masaje con la mezcla de manteca blanca de cerdo sin sal y mantequilla sin sal.

- Hojas de "matagallo" aplicadas en el vientre.

- Infusión de hojas de hierbaluisa sola o con anís en grano.

- Infusión de flores de manzanilla.

- Masajear y tomar en ayunas de una mezcla de vinagre, aceite y manteca blanca sin sal a partes iguales.
- Infusión en ayunas de manzanilla amarga. No tomar al día más de tres infusiones porque baja la presión.

\section{Dolor de barriga de los animales.}

- Infusión de tallos y hojas de fresno. Cocer en un litro de agua y reducir a la mitad.

\section{Dolor de estómago.}

- Aplicación local del ungüento producido al freír bellota de adormidera en aceite.

- Infusión de malva varias veces al día. Se utiliza toda la planta aunque la flor es más eficaz.

- Infusión de tallos y hojas de unciana.

\section{Dolor de vientre.}

- Infusión de "morau".

\section{Estreñimiento.}

- Comer un racimo de uvas en ayunas.

- Beber un zumo de naranja con una cucharada de aceite de oliva.

\section{Empachos.}

- Emplasto sobre el estómago de cebolla blanca, apio, sal y vinagre bien triturado en el mortero. Se sujeta con una gasa o venda.

- Manteca blanca sin sal extendida sobre el vientre y cubierta con una hoja de col.

\section{Fatigas.}

\section{Gases.}

- Infusión de guisopilla encima de cada comida.

- Infusión de anís estrellado en cualquier momento.

\section{Hemorroides.}

- Raíz de cardo "mujera" liada en un paño y guardada en el bolsillo. Conforme se va secando la raíz se secan las hemorroides.

- Aplicar como pomada la mezcla derretida de mantequilla sin sal y manteca de cerdo o margarina. Alivia el dolor y picor, según nos dicen.

- Pelotitas de "cardo de lidia" guardadas en el bolsillo.

- Cebolla "almorrana" debajo de la cama. 
13. Hernias en el niño.

- Piel de lagarto sobre la hernia. Cuando al lagarto le nace una nueva piel la hernia se cura.

14. Hernias en el recién nacido.

- Añadir a la papilla del niño pasta de batata de helecho macho cocida.

\section{Limpieza de estómago.}

16. Expulsión de lombrices internas. Se las conoce también como "ronzones".

- Infusión de hierbabuena y menta.

- Tomar en ayunas ajos macerados en vinagre una noche al sereno.

- Tomar nueve días en ayunas nueve ajos y después, vino. Otro entrevistado admite la posibilidad de tomar números "nones"(impares) de ajos.

- Infusión de tallos y hojas de hierbabuena. Es un aromatizante del caldo y del café que se puede utilizar como remedio masticando una ramita.

\section{Parásitos intestinales.}

- Beber vino al que se deja en maceración una cabeza de ajos cortada en trozos.

\section{Purgante.}

- Infusión de bayas de hiedra en ayunas o al acostarse.

\section{Problemas de digestión.}

20. Problemas digestivos. El encuestado no precisaba más.

\section{Tenias.}

- Infusión de nueve ajos o números "nones" (tres o siete) en ayunas durante nueve mañanas.

\section{2. Úlceras de estómago.}

- Infusión de unciana en ayunas. Se puede endulzar con miel. Otro encuestado afirma que se debe tomar nueve mañanas en ayunas y se descansan otras nueve.

23. Vómitos.

- Infusión de "yerbabuena” (hierbabuena).

\section{TRASTORNOS GENITOURINARIOS.}

\section{Cálculos.}

- Infusión de flor de higo chumbo seca.

- Vapores vaginales de infusión de romero.

\section{Expulsión de cálculos.}

- Beber a discreción de una infusión de tres tallos de "cola de caballo" en un litro de agua.

- Beber cuanto se quiera de infusión de "rompepiedra" preparada en un litro de agua. No se usa la raíz según nos especifican.

\section{Dolores de "entuerto". Son los posteriores al} parto, a partir del segundo o tercer hijo, al contraerse el útero.

- Preparado de dátiles en anís fuerte unos meses antes. Comer varios y tomar una copa.

- Infusión de granos de anís, canela en rama y cominos.

- Taza bien cargada de chocolate "del antiguo".

- Tijeras abiertas sobre el vientre.

\section{Dolor de parto.}

- Vapores de infusión de tallos, hojas y flores de malva.

5. Dolor de regla. Más adelante se indican otros remedios bajo otros epígrafes citados por distintos informantes.

- Infusión de cáscara de naranja seca cuanto se quiera.

\section{Dolor de riñón.}

- Infusión de rompepiedra para expulsar la arenilla, nueve mañanas en ayunas y descansando otras nueve mañanas.

\section{Menstruación.}

- Infusión en ayunas de hojas de nogal.

\section{Menstruación dolorosa.}

- Beber una copa de anís con pepino en maceración.

- Copa de ginebra o de anís dulce o seco en cualquier momento.

\section{Facilitar la menstruación.}

- Plantilla colocada en los pies de salvia real.

- Infusión en ayunas de ruda. La planta puede 
estar fresca o seca. Tomada tres días seguidos provoca la menstruación. Igual efecto inhalando los vapores de su cocción.

- Infusión en ayunas de orégano (toda la planta menos la raíz).

- Colocar en la cabeza y plantas de los pies, tallos, hojas y flores de rúa. Vendar y dejar unas horas. Alivia el dolor de barriga.

- Infusión de hojas de hiedra, hojas de laurel, perejil, comino, anís verde (del de cocinar) y canela en rama.

- Ducha de agua caliente en el bajo vientre.

- Infusión en ayunas de canela en rama y perejil. Es una fórmula usada antiguamente para abortar.

\section{Expulsión de la placenta de los animales.}

- Cuaerda atada a la placenta y a una piedra.

- Ramas de torbisca atadas en el cuello, cola y barriga del animal.

\section{Problemas de albúmina.}

- Infusión de ramas y hojas de olivo manzanillo en ayunas durante nueve mañanas.

\section{Retención urinaria.}

- Infusión de hojas secas de peral en la cantidad que se desee.

- Infusión de la seda de una mazorca de maíz cuanto se quiera.

\section{Infecciones de vagina.}

- Baño de asiento en infusión de hojas y flores de malva.

- Lavados con infusión de hojas de té.

\section{TRASTORNOS DEL APARATO LOCOMOTOR}

\section{Artrosis.}

- Aplicación local de aceite de oliva en el que fríen hojas y flores de romero.

\section{Ciática.}

- Pasar bayón por la zona dolorida. Se nota la mejoría a partir del tercer día.

\section{Contusiones.}

- Compresas empapadas en infusión de raíz, flores y tallos de árnica. La infusión tiene que estar muy fría para aplicarla. Puede producir daño en el hueso.

\section{Dolores.}

- Infusión o aplicación de compresas empapadas en una cocción de romero.

- Emplasto de retama y una cabeza de ajos bien machacada. No se debe dejar mucho tiempo porque puede provocar daño en el hueso.

\section{Dolores de artrosis.}

- Fresno y romero.

\section{Dolores "asiáticos".}

- Infusión de bulbo y hojas de cebolla.

\section{Dolores de gota.}

- Infusión en ayunas durante tres días de gobiernazo. Si no se presenta mejoría repetir otros tres días. Es muy amargo y no se debe endulzar.

\section{Dolores de huesos y articulaciones.}

- Sumergir el miembro afectado en infusión de orégano. Aplicar después un paño para conservar el calor.

\section{Dolores musculares.}

- Aplicación local de aceite en el que se fríe bellota de adormidera.

- Infusión de tallos, hojas y flores de orégano.

- Correa (cinturón) de piel de caballo curtida. Nos precisa el entrevistado que las personas sensibles a esta piel no lo pueden utilizar ya que les puede aumentar el dolor.

- Paños empapados en infusión de hojas de pita, corteza de encina dulce y ajos machacados y mezclados.

- Infusión bebida o paños empapados y aplicados localmente de resina de pino.

\section{Dolores de reuma.}

\section{Esguince.}

- Emplasto de sal, vinagre y retama (toda la planta menos la raíz).

- Aplicar la pomada que se produce al cocer y triturar hojas de cebolla, manteca blanca sin sal y miga de pan templada. 


\section{Inflamaciones.}

\section{Ligamentos.}

\section{Luxaciones.}

\section{Reuma.}

- Infusión encima del desayuno de hojas y flores de jara.

\section{Roturas.}

\section{Tendones inflamados y tirón muscular.}

- Aplicar sobre la zona una mezcla de alcohol, aguarrás, amoníaco y media cucharada de aceite (bien disuelto y agitado).

\section{Torceduras.}

\section{ENFERMEDADES DEL APARATO}

RESPIRATORIO

\section{Amigdalitis.}

- "Pella" (es la grasa de la gallina) secada y cortada en trozos. Calentar hasta derretir y aplicar como pomada bien extendida.

\section{Asma.}

- Piña silvestre colgada del pecho.

- Inhalación de vapores de hojas secas de eucalipto macho. Según nos precisan, el eucalipto macho tiene la hoja más ancha.

- Infusión de orégano, toda la planta menos la raíz, varias veces al día.

\section{Catarros.}

\section{Catarros bronquiales.}

- Infusión de azúcar tostado y hojas y frutos de "sombreros".

- Infusión de hojas, tallos y' flores de la flor de sauco.

- Inhalación de vapores de tallos y hojas de mejorana, eucalipto y poleo.

- Infusión de higos, de higuera bravía, higos chumbos, algarrobas tostadas y la cáscara de tres altramuces secos.

- Inhalación de vapores de malva, cebolla y diente de ajo.
- Infusión de borraja, neota y poleo a partes iguales a lo que se añaden un par de higos secos y varios trozos de algarroba.

- Inhalación de vapores de tallos y flores de almorahín.

\section{Hipo.}

- Colocar una pequeña bola de lana en la frente.

\section{Hipo en el recién nacido.}

- Beber unas gotas de limón.

\section{Infecciones de garganta.}

\section{Problemas de alergia.}

- Inhalación de vapores de unciana, poleo, cáscara de piña (de pino), de plátano y de algarroba.

\section{Problemas de bronquios.}

\section{Problemas pulmonares.}

- Infusión o inhalación, más corriente, de meloncillo bravío recogido en verano, toda la planta menos la raíz.

\section{Problemas respiratorios.}

- Inhalación de vapores de hojas de eucalipto.

- Infusión de tallos, hojas y flores de neota.

\section{Resfriados.}

- Infusión varias veces al día de una mezcla tallos y hojas secas de guisopilla, poleo, y neota.

- Infusión de "hierba de las siete sangrías" cortada en trozos y secada, toda la planta menos la raíz, endulzada con miel y azúcar.

- Infusión de tallos y flores de tomillo y orégano en ayunas. Las plantas deben recolectarse en julio, con luna menguante.

- Emplasto de ceniza de leña o carbón mezclada con aceite de oliva. Untar sobre el pecho y la espalda y cubrir con papel de estraza.

- Infusión de hojas de poleo solas o con cortezas de naranjas amargas.

- Mantener ajo crudo en la boca el máximo tiempo posible y luego hacer gárgaras.

- Ajo rallado en maceración con zumo de limón durante unos minutos. Se agrega agua y se bebe lo que se desea. 
- Infusión de poleo, neota y manzanilla endulzada o no con miel.

- Zumo templado de naranja agria mezclado con zumo de naranja no agria endulzado con miel.

- Infusión de neota. Con el poleo, el efecto parece ser mayor.

- Infusión de poleo, algarroba y menta después de las comidas.

- Infusión de poleo solo o unido a neota y algarroba antes de acostarse y endulzado con miel. El poleo se puede tomar solo, con leche, en ayunas y en la cama. Despeja las vías respiratorias.

- Leche caliente con cognac. Ayuda a "sudar" el resfriado.

- Infusión con la flor, hojas y tallos de poleo, neota, pericón, a la que se añade higo seco, algarroba, piel de naranja y miel. Estas hierbas se hierven en doscientos cincuenta mililitros de agua. Se añade azúcar o miel. Se aconseja tomarlo bien caliente, acostarse y arroparse bien para "sudar el resfriado". Si es necesario tomar de tres a cuatro infusiones, según mejoría, y siempre al menos una vez al día y por la noche antes de dormir. Las plantas se deben recoger a finales de mayo o principios de junio, con la flor totalmente formada. Después se secará y se guardará en un sitio fresco y seco. La piel de naranja debe estar también seca.

\section{Ronquera.}

- Infusión de tallos y hojas de borraja.

\section{Tos.}

- Tomar una cucharada de vino dulce calentado y unas hojas de amapola.

- Infusión del fruto del higo chumbo rojo (debe estar maduro).

- Zumo de limón y miel.

- Cebolla colgada en la habitación. También se puede poner en un recipiente con agua.

- Tomar dos cucharadas de miel y unas gotas de limón.

\section{Tos difícil.}

\section{Tos con inflamación de garganta.}

- Zumo templado de limón y naranja amarga endulzado con miel y bebido a sorbos. Permite calmar el dolor.

\section{Tosferina.}

- Beber agua de nueve fuentes durante nueve días en ayunas.

\section{MAL DE OJO}

Son varios los remedios aportados por las personas encuestadas. Se transcribe, además, información adicional que fue aportada por una entrevistada con supuestos poderes curativos.

1. Oración recitada por la mañana como mínimo durante veinte días. No se puede revelar porque perdería su poder.

2. Tomar en ayunas bicarbonato mezclado con una cucharadita de limón. Además poner una cruz de "torbisca" debajo de la almohada y ramas de este arbusto debajo del colchón.

3. Inhalar vapores de eucalipto y poner una cruz de "torbisca bajo la almohada o el colchón.

4. PARA ADULTOS. Hervir una pequeña cantidad de eucalipto macho en dos litros de agua, reponiendo cada cocción y nunca tirando el agua que ha quedado de una vez a otra, sólo el eucalipto. Tomar la punta de una cuchara llena de bicarbonato y una cucharada de zumo de limón mezclados.

Durante nueve noches inhalar vapores de eucalipto. Acostarse seguidamente sin tomar frío y durante nueve mañanas ingerir la mezcla de limón y bicarbonato en ayunas.

Poner una cruz de torbisca debajo de la almohada durante cuarenta días. Después quemarla deshaciendo la forma de cruz.

5. PARA NIÑOS. Tomar nueve mañanas en ayunas la mezcla de limón y bicarbonato. En este caso se utiliza una cucharada de postre. Si se trata de neonatos sólo usar unas gotas de limón y una pizca de bicarbonato.

Se fríe romero (tallo y hojas) en unos tres dedos de aceite. Con este aceite de romero, se da un masaje en la espina dorsal hasta los pies, incluyendo los brazos y siempre en dirección hacia el suelo, durante nueve noches.

Colocar durante tres días debajo de la almoha- 
da la cruz de torbisca y después ponerla en un saquito con ramas del arbusto durante cuarenta días.

Tanto en los adultos como en los niños, se recitan oraciones encomendadas a santos. Éstas se recitarán durante nueve noches y en el nombre de la persona afectada que pueden ser "Ave María" y "Padre Nuestro".

Nuestra informante, que además es sanadora, nos indicó que acuden a ella desde hace aproximadamente unos ocho años cuando se corrió la voz que curaba el "mal de ojo". Actualmente recibe gentes de distintos lugares y con variado nivel cultural.

Son personas que se sienten un malestar extraño $o$, en otros casos, porque han acudido al médico y no han sentido mejoría. Los síntomas son fiebre (niños), vómitos, diarreas, dolor de estómago, tristeza o malestar general.

Interrogada sobre algunos casos, síntomas y tratamientos aplicados nos citó varios:

- Señora con hipertensión arterial tratada farmacológicamente y que cuando acude a ella no está controlada. Lo que le descontrolaba era este mal. Le indicó el tratamiento para adultos y a los cuatro días mejoró de su tensión.

- Niño de veinte días que vomitaba toda la leche que mamaba. El médico lo atribuyó a los calostros, pero la sanadora afirma que era mal de ojo. Le indicó el mismo tratamiento que para los niños pero en menor cantidad y a los tres días de tratamiento volvió a mamar sin vomitar y tomando peso.

- Otros niños con pérdida de apetito, insomnio, tristeza y algunas veces décimas de fiebre. Ella le ha diagnosticado el mal de ojo, les ha puesto tratamiento y a los pocos días han mejorado recobrando el apetito. (Nos precisa la sanadora que algunos habían recibido tratamiento pero la mayoría no).

Por otra parte, esta mujer considera que no todas las personas que acuden a verla padecen de "mal de ojo". En estos casos los remite al médico o les prescribe algo para lo que padecen ya que es "naturista" desde hace cinco años.

Nos intenta describir que es el "mal de ojo":

"Son radiaciones magnéticas negativas que se introducen en los cuerpos vivos, produciendo alte- raciones de la salud y del organismo. Hay personas que tienen la facultad de producir radiaciones negativas. Estas personas expulsan al exterior de su cuerpo esas radiaciones cuando están sobre cargados. La radiación se expulsa al exterior cuando la persona que la produce se lleva un gran sobresalto o un disgusto que la excite el sistema nervioso o cuando siente una gran admiración por algo que les atraiga más de lo normal. Cuando sucede esto, si se encuentran alguna otra persona frente a su mirada, a esta última, se le introducen en su cuerpo estas radiaciones negativas. $\mathrm{Si}$ en ese mismo instante, a la persona que recibe las radiaciones negativas se le provoca de alguna forma llanto, quedará inmediatamente liberado de las fuerzas de las radiaciones negativas recibidas.

Existen otras personas que producen radiaciones magnéticas positivas y pueden anular los efectos que producen las negativas. Para conseguir esto, las personas dotadas de esta facultad rezan oraciones clave encomendadas a santos y fuertes concentraciones mentales con deseos propios que la persona afectada se cure, además de recurrir a la torbisca en forma de cruz. Cuando ésta se seca, tras un número determinado de días, el paciente se debe curar".

Otro remedio para el "mal de ojo" resulta de la combinación de plantas, algunas ya citadas, y de oraciones que en este caso sí nos revelaron: se empieza haciendo una cruz en la frente y en cada ojo con el dedo pulgar, a la vez que se recita la oración que sigue (siempre en primera persona)

$$
\begin{aligned}
& \text { "Mal de ojo, maleado } \\
& \text { dos ojos te dañaron } \\
& \text { tres te sanaron". }
\end{aligned}
$$

Además se reza un "Padre Nuestro", un "Ave María" y un "Gloria". Se tiene que tomar limón con bicarbonato en ayunas durante nueve mañanas, colocar ramas extendidas de torbisca por toda la cama, bajo el colchón y una cruz de torbisca debajo de la almohada.

\section{ASISTENCIA A CURANDEROS}

Del total de personas encuestadas, contestaron sobre asistencia o no a curanderos treinta. De estas, veintidós negaron acudir mientras que ocho sí con- 
fesaron recurrir a los curanderos. Se transcriben, seguidamente, las respuestas dadas.

1. Acude desde hace cinco años al curandero de la estación de Caucín por necesidad y por creer en la medicina popular. Una vecina había tenido su mismo problema y se lo recomendó. Padecía "mal de ojo".

2. Acude desde hace diez años al mismo curandero que el anterior, por creencia y por iniciativa propia. Padecía de "mal de ojo". Mejoró.

3. Recurre a un curandero de Ubrique por presentar una "culebrina" en la boca. No tuvo mejoría con la medicina convencional. Utilizó esparto y salmuera durante nueve días además de recitar una oración. La mejoría se produjo a partir del tercer día. En las cuatro semanas anteriores estuvo en tratamiento médico por su menopausia.

4. Acude esporádicamente a curanderos de diferentes lugares por dolores de hueso. Le aplicó "frotaciones". Hubo poca mejoría.

5. Acude a curanderos desde hace aproximadamente unos 25 años por dolencias diversas en la cabeza. Siempre se han curado. No le recomendaron nada, salvo no mojar la parte afectada en nueve días. Esta persona nos dice que en Ubrique varias personas se dedican al conjuro de ciertos malestares o enfermedades por mediación de hierbas, oraciones y otros procesos naturales.

6. Una señora que asiste a un curandero señala que "se trata de una persona que tenía una gran fuerza".

7. Un señor comenta que fue a la consulta del curandero de la estación de Caucín en dos ocasiones en los últimos quince años.

En una de ellas su hija estaba enferma y el médico no conseguía curarla. Le prescribe durante nueve días limón con bicarbonato en ayunas, masajes antes de dormir con aceite en el que se había frito romero, vapores de eucalipto macho también antes de dormir, unas matas de torbisca debajo del colchón y una cruz de torbisca debajo de la almohada. Además de estos remedios físicos, la curandera recitaba rezos y oraciones durante nueve días. Previamente, sólo había recibido tratamiento médico para una afección de garganta. La dolencia desapareció.

Pero también hay casos que defienden posiciones diametralmente opuestas.

8. Un entrevistado afirma que de "dos casos que he conocido de cerca, ambos fueron fallos estrepitosos; creo que la ciencia médica tiene más garantías". Sus conocidos acudían a la estación de Colmenar. Les mandó eucalipto macho, torbisca y oraciones de la curandera "entre vistazo y vistazo al cocido en una casa contigua". Ninguno de los casos mejoró y en uno de ellos hubo que ingresar en un hospital a un niño por deshidratación en estado bastante grave.

9. Otra persona contesta que no acude a curanderos porque no cree en ellos, aunque conoce alguno y sabe de personas que van a ellos. Sí acepta el poder de algunas plantas medicinales aunque recurre poco a ellas: tila, cuando está alterado, manzanilla, té o plantas parecidas.

Una única vez usó cebollas contra las hemorroides aconsejado por unos amigos. En principio fue reticente para su empleo, pero al no tener que ingerir nada ni aplicarse sobre el cuerpo, decidieron probarlo. A ellos, les fue efectivo.

10. Una encuestada ha acudido al curandero varias veces porque éste le curaba el "mal de ojo" cuando lo padecía.

Acude al curandero de la estación de Caucín. Le recomienda limón en ayunas, vapores con hojas de eucalipto y hojas de torbisca. Presentó mejoría a los cuatro días. Sin embargo, después de este episodio debió recurrir al médico para expulsar "las balsas".

Esta persona tiene la facultad de curar la "culebrina" a distancia empleando únicamente una fotografía de la persona a curar.

\section{¿DE QUIÉN APRENDIÓ LOS REMEDIOS?}

Han contestado a esta cuestión 38 entrevistados y los resultados son los que siguen:

1. Padres $=18$.

2. $\operatorname{Vecinos}=6$. 

3. Hermanos $=2$.
4. Abuelos $=7$.
5. Jefes $=1$.
6. Suegros $=2$.
7. Curandero $=2$.

\section{DISCUSIÓN.}

Aunque existe paralelismo con los remedios conocidos popularmente y que son generales en amplias zonas de nuestro país, aparecen ciertas particularidades que son interesantes de remarcar.

Llama poderosamente la atención la aparición reiterada del número nueve. Se repite este guarismo indicando las veces que hay que realizar un ritual o emplear un remedio para conseguir el efecto deseado. Ejemplo de este extremo es la curación de la ictericia, recitando una mañana de mayo una oración o ensalmo y orinando nueve mañanas sobre un roble escogido al azar por el enfermo. Otros casos son la realización de un conjuro nueve veces para conseguir la curación.

La utilización de amuletos en el bolsillo también es ampliamente realizada: castaña de Indias para el dolor de muelas, cardo "verde" guardado en el bolsillo esperando que se seque para que se vaya curando la diarrea.

Otros autores recogen, asi mismo, recogen influencias lunares y estacionales. El estado de la luna, por ejemplo, es importante a la hora de cortarse las uñas y que no crezcan frágiles o la recogida de plantas en la Ascensión por su efecto curativo, aspecto éste que coincide en la recogida de hierbas por San Juan por tener la naturaleza mayores propiedades terapeúticas. Se recoge, además, que las flores y plantas deben ser puestas en la ventana para tomar el rocío de San Juan (16) y que las mujeres estériles deben estar en la playa de Las Lanzadas en la noche de San Juan para recibir "as nave ondas". En esta misma noche, se pueden hacer ciertos sortilegios contra el "mal de ojo".

Al igual que en nuestro trabajo aparece descrita la utilización de animales para la curación de dolencias diversas. Es el caso de la sangre de lagarto para remedio de herniados. Plinio el Viejo parece que lo recoge como un recurso romano en el que el lagarto debía morder al niño y luego esperar a que muriese por desecación al colgarle vivo en algún lugar y esperar que sanase el niño.
Muchos son los productos empleados para el resfriado, aunque algunos presentan también añadidas utilidades terapeúticas: poleo y salvia, vahos de eucalipto, ruda, zarzaparrilla, agua de romero, agua de rosas, manteca de cerdo.

A la leche de burra se le atribuyen numerosas virtudes como aparece recogido en la obra de Sainz de Robles "Historias y Estampas de Madrid", donde se vendía directamente del animal.

Un proceso abordado de forma parecida en diferentes lugares de España, es la verruga vulgar. En ciertos pueblos leoneses, se arrojan tantos garbanzos como verrugas se tengan al agua de un riachuelo; habrá que seguirlos con la vista hasta que desaparezcan corriente a bajo. Se pueden tirar los garbanzos en número similar a un pozo. Una tercera opción la representa el recitar un conjuro y alejarse del lugar donde se han frotado las verrugas con granos de trigo, manzanas verdes, etc.

En los textos consultados, son numerosos los conjuros y remedios contra el "mal de ojo".La torbisca se utiliza bastante en este caso: arrojando la planta al tejado de una casa $y$, mientras la planta se seca, desaparece el aojamiento. Se emplea en forma de cruz o en una bolsa.

El ajo es un remedio también muy socorrido. En el Dioscórides se recomienda como vermífugo, además de remedio para los pulmones y los trastornos de estómago e intestino. El ajo macerado en vino es tomado por cuatro ladrones en 1721 que son liberados a condición de enterrar a los muertos de una gran plaga. El ajo cura catarros, otros procesos respiratorios superiores, granos en la piel, fiebre, reumatismo, cólera, y tifus, asma, tuberculosis, hidropesía, cáncer e hipertensión arterial .

Otros remedios comunes y citados por diferentes autores son: leche de mujer (morena) para el dolor de oídos, tela de araña para cortar las hemorragias recientes, piel secada de vesículas de cordero o de cerdo aplicadas muy calientes sobre los forúnculos, lana de carnero muy caliente en la zona dolorosa de la garganta (paperas).

La figura del sanador merece un comentario aparte. En los textos consultados, se menciona la "gracia" como el elemento que concede poderes sobrenaturales al sabio. Por otra parte, la propia clasificación de la enfermedad en natural y sobrenatural y la curación consiguiente por remedios 
naturales y/o en combinación con otras intervenciones, resalta la misma figura del curandero.

Aunque nuestra muestra es escasa, la asistencia a curanderos no es seguida por la mayoría de los entrevistados. No obstante, hay que considerar el elemento vergonzante que puede existir para estas personas al reconocer su creencia en tales prácticas y que en el presente trabajo no es considerado. De cualquier manera, la misma dualidad de actitudes frente al curanderismo probablemente refleja dos posturas con respecto a la Etnomedicina: los que la consideran heredera de creencias o tradiciones nigrománticas en el transcurso de la historia frente a los que aceptan una adaptación de la misma a las nuevas circunstancias culturales y sociales fruto de la evolución, partiendo del hecho que la curación por hierbas eran usados por primates no humanos y constituyen la base de las prácticas curanderas indígenas en todo el mundo.

Hay que resaltar que la asistencia a los curanderos y la utilización de los remedios no se decanta claramente sobre procesos crónicos. En nuestro caso, el grupo de enfermedades abordadas sigue una distribución bastante proporcionada entre procesos crónicos y agudos.

Resulta evidente remarcar que estas prácticas pueden resultar peligrosas probablemente relacionado con la creencia en la inocuidad de todos estos remedios. Por un lado, podemos referirnos al comentario vertido por una entrevistada citando el caso de un niño que sufrió una deshidratación y requirió asistencia urgente. Por el contrario, hay instituciones oficiales, como el Centro Andaluz de Información del Medicamento) que previenen sobre el uso de determinados productos farmacéuticos, cuya base son las raíces de la planta ginseng por presentar efectos indeseables.

De cualquier manera, la importancia de estas prácticas queda reflejada en la celebración del pri- mer congreso en España de medicinas alternativas con participación de profesionales de distinta titulación. La extensión de estos conocimientos a la Universidad en países como EEUU. remarca la importancia de este tipo de conocimientos.

\section{BIBLIOGRAFÍA.}

Alonso BilbaO, J.L. (1996) Tipos de estudio. Muestreo. Salud Pública y Educación para la Salud ( Macías Gutiérrez, B.E., Arocha Hernández, J.L. Eds ), ICEPSS, Las Palmas p. 160.

Binding, G.J. (1980) El Ajo. EDAF, Madrid p. 39.

CADime / Escuela andaluza de Salud Pública. (1997) Ginseng: usos y peligros. Boletín Terapeutico Andaluz 5, 20.

Carril, A. (1991) Etnomedicina. Acercamiento a la terapeútica popular. Castilla, Valladolid pp. 1220.

Consejo Andaluz de Enfermería. (1997) Primer Congreso de Medicinas Alternativas. Enfermería Actualidad pp. 10-11.

Fresquet Febrer, J.L. (1995) Salud, enfermedad y terapeútica popular en la Ribera Alta. Instituto de Estudios Documentales e Históricos sobre la Ciencia, Universitat de Valencia - CSIC, Valencia.

GoRdon, J.S. (1997) Medicina Alternativa y Médico de Familia. American Family Physicians (ed. española) 3,119 .

KuschiK, I. (1995) Medicina popular en España. $1^{a}$ ed. Siglo XXI de España, Madrid p. 141.

Patt-Rivers, J. (1965) Un pueblo de la Sierra: Grazalema. Alianza, Madrid p. 206.

Rua Aller, FJ., Rubio Gago, M.E. (1990) La medicina popular en León. Leonesas, León p. 12.

VÁZqueZ GaLLEGo, $\mathbf{X}$. Tradiciones, mitos y creencias y curanderismo en medicina Popular de Galicia. Servicio de Publicaciones de la Diputación Provincial de Lugo, Lugo p. 68. 